\title{
Lecturas Vinculares: un análisis de los libros sobre hábitos, dirigidos a la infancia en edad temprana
}

Nati Calvo Buil, Servei de Documentació de Literatura Infantil i Juvenil (Biblioteques de Barcelona)

\section{Lectura vincular en la edad temprana}

El mundo de la infancia de 0 a 3 años gira en torno a las experiencias y aprendizajes vinculares a partir de las rutinas del día a día. Esta realidad nos permite abordar la lectura en esta etapa desde esta perspectiva, construyendo un enfoque metodológico para valorar los cuentos sobre los hábitos infantiles que pautan el tiempo diario y el paso de un estadio de crecimiento a otro. Si el niño/a se vincula a la cotidianidad mostrada por esos cuentos a partir de la suya propia, es interesante indagar si éstos reúnen características que nos permitan intuir si el pequeño/a, sólo o con ayuda de adultos, establecerá un vínculo con esas lecturas que formarán parte de su formación lectora y literaria.

Si intuimos que el pequeño/a emprende el camino hacia la lectura entrando y saliendo de los libros que le invitan a leer el mundo, la estrategia para este viaje debería construirse desde la sensibilidad, el planteamiento estético, la palabra clara y el juego, la intuición y el rito, la imaginación y la provocación. Este primer periplo literario podría llevar el nombre de lectura vincular, porque une y no ata, separa pero no abandona, permite construir y ayuda a aprehender.

Los pequeños siempre exploran, esperando que un día llegue el objeto-libro a sus cinco sentidos para llenar un hermoso hueco (Aberasturi 2002) y establecer un vínculo con la lectura. Si este acercamiento es motivado emotivamente por quienes le rodean, el niño/a se descubrirá en él recreando de nuevo el mismo libro cada vez que caiga en sus manos o le sea explicado (Colomer 2005). Esta exploración reiterada se convierte en lectura vincular.

Los mediadores necesitamos definir esta lectura en las primeras etapas a partir de los elementos indicados. Para nosotros, leer sería esa "capacidad humana para ordenar significativamente los signos sensoriales -que nos llegan a través de los sentidos - implicando en ello nuestra emotividad" (Duran 2002: 14). El universo lector que se abre a partir de esta definición invita y responsabiliza a los profesionales a 
aplicar un giro metodológico importante en nuestro trabajo. El niño lee porque se lee a sí mismo y, acompañado de nuestra sensibilidad, leerá a los otros y leerá el mundo que le rodea.

\section{La intrépida experiencia diaria de los más pequeños: el libro como espejo de todo lo posible... ¡y más!}

Cuando detectamos en la visión del artista un sentido infantil de la maravilla, también nos enfrentamos con los sentimientos de nuestros primeros descubrimientos, de cuando el mundo en lugar de rodearnos sencillamente se posaba frente a nosotros, aún sin nombres y sin profundas pretensiones 0 imposiciones de significados. (Lionni 2005:151)

Para fundamentar una valoración representativa de la realidad ha sido necesario seleccionar una muestra de libros partiendo del conjunto de hábitos que los niños de 8 meses a 3 años deben adquirir en esa etapa. Siguiendo las pautas de Evelyn Torres (2006), los descubrimientos que realiza el niño de esas edades parten en primer lugar de la exploración del "sí mismo" y más tarde del "mundo natural” y del "mundo social” (p. 102).

La comunicación continua del pequeño con los acontecimientos que ocurren diariamente es la base a partir de la cual él va adquiriendo la noción de su "lugar en el mundo” y "la manera particular de abordar el ser y el conocer” (Torres 2006: 107). Esta comunicación corporal requiere la percepción del sentimiento del sí mismo en el otro, factor importante que serviría de lugar de intendencia para detenerse en las figuras, tiempos y espacios que acompañan a los protagonistas de los cuentos seleccionados. La capacidad motriz de un niño en edad temprana, su tono y sus sentidos, se abren a la exploración del mundo que le rodea y a la lectura del mismo, conformándose ésta como una orquesta de ritmos pautados a partir de las rutinas del día a día. Éstas le ayudarán a “poner orden frente al caos” (Steiner 1996: 50): Levantarse, asearse y vestirse; la hora de comer; El baño vespertino y el camino de las Buenas noches recorren las 24 horas de su vida diaria desde la experiencia del presente ${ }^{1}$.

El proceso de decir Adiós a los pañales, situado actualmente entre los 24 y los 30 meses, también requería un acercamiento al proceso que culminará al final de esta importante etapa, a los 3 años de edad: “Todo lo que acontece alrededor del cuerpo del niño en esta edad temprana se convierte en referencia, en materia prima para elaborar 
capacidades y tendencias de acción, que no es otra cosa que la personalidad” (Torres 2006: 110).

\section{El laboratorio de las lecturas: seleccionando cuentos sobre hábitos}

La selección se trabajó a partir de materiales elaborados por profesionales, en el marco del proyecto Nascuts per llegir ${ }^{2}$, llevado a cabo en varios países europeos y, desde el año 2004, también en Cataluña. Este proyecto propone fomentar la lectura afectiva desde el primer mes de vida, haciéndose eco de otros proyectos nacionales e internacionales ${ }^{3}$.

Se contaba con dos guías de lectura publicadas cuyo contenido eran los libros sobre hábitos para niños/as en edad temprana: L'Aventura del dia a dia (2006) ${ }^{4}$ y A dins i a fora (2007), y otras dos guías que seleccionaban historias sobre el mundo que rodea al pequeño de 0 a 3 años, cuentos que relacionaban el ritmo de las palabras y el ritmo interno/externo del bebé: Salta Miralta (2006) y El món de l’infant (2005), respectivamente.

Decidir implica renunciar. La muestra final de cuentos intentó acotar una selecta representación de las diferentes propuestas de estilos y editoriales, teniendo que descartar otros títulos.

\section{Habilitando un modelo de análisis: el microscopio de las categorías}

Teresa Duran (1981) concreta las características que deberían tener los libros destinados a la infancia menor de 6 años:

[...] libros manipulables; dominancia de la imagen sobre el texto, debidamente claro y armoniosamente distribuido tipográficamente, sintácticamente correcto y adaptado a la capacidad de comprensión oral; con ilustraciones que no caigan en el realismo abusivo ni en el manierismo desbordado; trazos negros que resigan una imagen coloreada con tintas planas, mejor que con colores en directo; no sobreabundancia del color; formas bien resueltas y de percepción correcta ¡caricaturas abstenerse! -; perfil óptico óptimo, en vez de contrapicados y angulaciones excesivas” (p.25).

Eso sí, tras presentar esta adecuada normativa como referente, propone una condición que permitirá que las excepciones, tanto del libro como del lector, confirmen las reglas: “el libro ha de fascinar, estimular el deseo... La comunicación con el libro es más real cuantos más sentidos ha satisfecho” (Duran 1981: 26). 
El Banco del Libro, dentro de su colección Formemos lectores, realiza una subdivisión de las edades dentro de la edad temprana y propone dos fases relacionadas con etapas importantes en el crecimiento: de 8 meses a 2 años y de 2 a 6 años, por lo que en la segunda se incluiría también el periodo de 2 a 3 años (AAVV 2001; 2001b). En el primero de los dos apartados citados se habla también de libros manipulables, resistentes y no tóxicos; ilustraciones con personajes cercanos al mundo del bebé; narraciones ágiles, breves y sencillas; rimas y canciones breves que favorezcan la lectura en voz alta. Y en el segundo se introducen los álbumes donde "la ilustración y el texto cuentan la historia” (Colomer 2005: 41), y cuyas imágenes amplían la sensibilidad estética de los niños, con ilustraciones que los invitan a contar sus propias historias.

Por tanto, observamos que ambas propuestas permiten valorar un producto de calidad, adaptado a la edad temprana. Ambas sirven para definir un instrumento metodológico que debería reflejar:

La expresión de las vías narrativa y visual:

- Si la narración se reparte entre texto e ilustración; si el primero invita a ser narrado por un adulto y si ambos ayudan o no a la “alfabetización” de la que habla Lionni (2005: 151) y si está bien expresado y tramado. O si el argumento no es narrativo, pero permite una "coherencia adecuada que secuencie todos los elementos integrantes” (Silva-Díaz 2006: 27) desde un tono descriptivo que relate el hábito paso a paso, con elementos literarios que irán proyectando en su mundo ficticio propio todo aquello que el niño/a va aprehendiendo de su mundo real cotidiano (Bruel 2003: 89)

También se creyó importante señalar aquellas narraciones con elementos metaficcionales que demandaban ya de los pequeños y de los adultos una mayor interacción lúdica (Silva-Díaz 2005: 21), saliéndose de lo común en estas primeras historias sobre hábitos.

-Si la sintaxis de las ilustraciones tiene una carga realista o simbólica y si la vía comunicativa escogida por el ilustrador se expresa a través de la empatía afectiva, “apelando al corazón” y/o ingeniosa, “apelando también a la inteligencia” (Duran 2007: 96) ${ }^{5}$.

-Tratándose de hábitos y, por tanto, del mundo cotidiano de los más pequeños, definir cómo son tratados los paratextos, contornos, formas, colores, fondos y contrastes, en suma, el equilibrio en la composición y el ritmo de las ilustraciones, se intuyó como una posibilidad de ilustrar con eficacia -en la acepción de aportar luz al conocimiento- la narrativa visual de los hábitos diarios del niño/a. 
Cómo se representa, se nombra y se contiene el mundo que rodea a los niños:

-Si el entorno del cuento es reflejo del entorno que vive el pequeño en las tres etapas de su crecimiento entre los 8 meses y los 3 años; si muestra la necesidad del vínculo que el niño establece con todo aquello que deviene un referente en su mundo cotidiano; si es, a la vez, capaz de ofrecer un espacio afectivo o lúdico de lectura; y si posibilita los "logros" que cada final de etapa particular requiere ${ }^{6}$.

Qué formato precisan:

-En otras palabras: cómo los editores se las ingenian para repartir la producción editorial, combinando formatos y respondiendo a los distintos enfoques de este tipo de libros que conducen afectivamente al entretenimiento y/o a la educación de los hábitos.

A partir de estas orientaciones más integrales, ampliadas por otros autores que desarrollan algunos de los aspectos señalados ${ }^{7}$, se trazaron un conjunto de categorías y subcategorías a tener en cuenta en el análisis de los cuentos sobre los hábitos del sí mismo para los más pequeños:

\section{Marco argumental}

o Texto

- Argumento Narrativo o Visual

- Hilo argumental (¿quién narra la historia?)

- Bebé o figura protagonista que lo sustituye

- Miembros de la familia

- Narrador o personaje externo

- Discurso argumental

- Descriptivo/Didáctico

- Imaginativo/Literario

- Desenlaces

o Ilustración

- Realista

- Simbólica

- Análisis de las ilustraciones

Entorno físico y psicológico del pequeño/a o protagonista en el cuento

o Representación del pequeño/a o protagonista

o Representación de la familia 
o Representación de otros personajes

o Representación de los espacios y el tiempo

\section{Criterios editoriales}

o Formatos

- Pequeños lectores

- Álbum ilustrado

- Libro sorpresa

o Ejes de la oferta

- Lúdicos

- Afectivos

- Educativos

\section{Interpretando los cuentos sobre hábitos ${ }^{8}$}

\section{Es hora de levantarse, lavarse y vestirse}

\begin{tabular}{|c|c|}
\hline $\begin{array}{l}\text { Marco argumental: } \\
\text { texto }\end{array}$ & $\begin{array}{l}\text { - Argumentos mayoritariamente textuales (excepto La meva roba) y } \\
\text { descriptivos. } \\
\text { - Narración generalmente en tercera persona. } \\
\text { - Tonos afectivos. } \\
\text { - Aparece la simbolización que bien rompe el tiempo real (Lleva't), bien aborda } \\
\text { la metaficción (Em vesteixo i et menajaré!). } \\
\text { - Desenlaces sin rigidez y positivos, supeditados al aprendizaje del hábito. }\end{array}$ \\
\hline $\begin{array}{l}\text { Marco argumental: } \\
\text { ilustración }\end{array}$ & $\begin{array}{l}\text { - Mayor presencia del simbolismo frente al realismo. } \\
\text { - Vía empática afectiva e ingeniosa, con marcada presencia de los animales como } \\
\text { protagonistas. }\end{array}$ \\
\hline $\begin{array}{l}\text { Entorno físico y } \\
\text { psicológico }\end{array}$ & $\begin{array}{l}\text { - Espacios limitados a la habitación y a los objetos relacionados con el } \\
\text { aprendizaje. } \\
\text { - Mínima presencia de figuras paternas (la madre aparece en Bon dia!). } \\
\text { - Mayoritaria presencia de personajes no familiares. } \\
\text { - Los objetos transaccionales }{ }^{9} \text { interactúan con imaginación, humor e } \\
\text { intertextualidad. } \\
\text { - En algún caso aparece la dimensión del tiempo imaginario (Lleva't). }\end{array}$ \\
\hline Formato editorial & $\begin{array}{l}\text { - Predominio del formato àlbum o libro sorpresa cuando el argumento tiene carga } \\
\text { simbólica (Em vesteixo i et menjaré!, Lleva't). } \\
\text { - Presencia de las ofertas lúdicas, afectivas y educativas, especialmente las dos } \\
\text { últimas. }\end{array}$ \\
\hline
\end{tabular}

Tabla 1. Análisis del corpus de cuentos sobre los hábitos de levantarse, lavarse y vestirse 


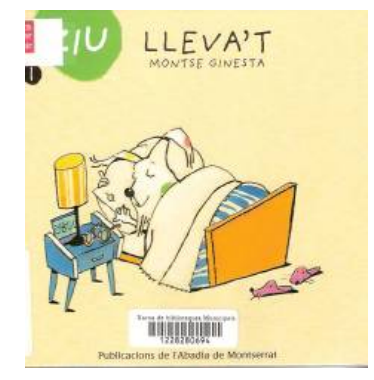

Ilustración 1. (C) M. Ginesta. Lleva’t. Barcelona: Publicacions Abadia de Montserrat, 2004.

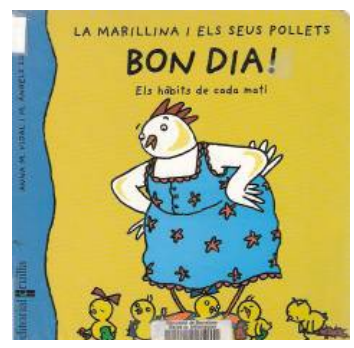

Ilustración 3. (C) A. Vidal, A. Comella. Bon dia!. Barcelona: Cruïlla, 2001.

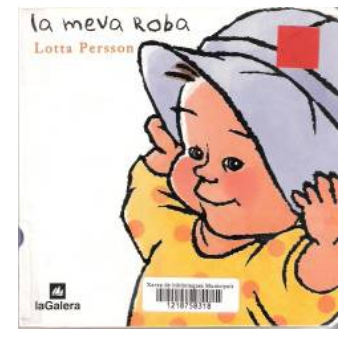

Ilustración 2. (C) L. Persson. La meva roba. Barcelona: La Galera, 2003.

\section{¡A comer!}

\begin{tabular}{|c|c|}
\hline $\begin{array}{l}\text { Marco argumental: } \\
\text { texto }\end{array}$ & $\begin{array}{l}\text { - } \quad \text { Argumentos textuales, excepto Kimba a taula. } \\
\text { - } \\
\text { matgumento de mano del protagonista y sus padres, dominando la figura } \\
\text { - } \quad \text { Tono afectivo. } \\
\text { - } \quad \text { Discurso literario al introducir el concepto tiempo o repetición (No tinc gana!) } \\
\text { Desenlaces supeditados al aprendizaje del hábito. }\end{array}$ \\
\hline $\begin{array}{l}\text { Marco argumental: } \\
\text { ilustración }\end{array}$ & $\begin{array}{l}\text { - Simbolismo en la utilización de animales. } \\
\text { - Vía empática afectiva mostrando el realismo del aprendizaje del hábito } \\
\text { (regresiones en Bon profit, Max! o autonomia en Ruby, anem a dinar!). }\end{array}$ \\
\hline $\begin{array}{l}\text { Entorno físico y } \\
\text { psicológico }\end{array}$ & $\begin{array}{l}\text { - La comida como aprendizaje lúdico. } \\
\text { - Presencia mayoritaria de una figura materna dotada de una gran paciencia. } \\
\text { - Tan solo en Ruby, anem a dinar! la figura paterna ejemplifica la igualdad de } \\
\text { género. } \\
\text { - Espacios cotidianos relacionados con los hábitos. } \\
\text { - Muñecos convertidos en objetos transaccionales. } \\
\text { El tiempo se supedita al aprendizaje del hábito, excepto en argumentos más } \\
\text { literarios que no tienen linealidad (Ruby, anem a dinar!). }\end{array}$ \\
\hline Formato editorial & $\begin{array}{l}\text { - Predominio de tapa dura. } \\
\text { - Aparece el álbum ilustrado cuando el discurso es más literario (Ruby, anem a } \\
\text { dinar!). } \\
\text { - Hegemonía de las ofertas lúdicas, afectivas y educativas. }\end{array}$ \\
\hline
\end{tabular}


Tabla 2. Análisis del corpus de cuentos sobre el hábito de comer

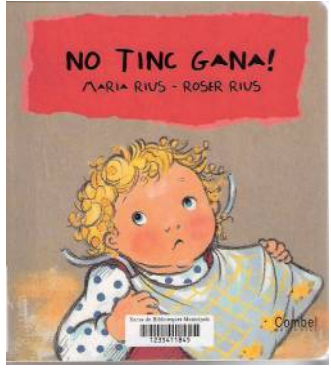

Ilustración 4. (C) M. Rius; R. Rius. No tinc gana! Barcelona: Combel, 2004.

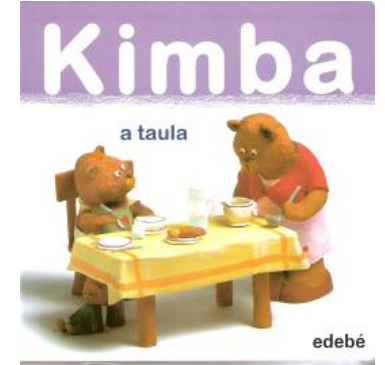

Ilustración 5. (C) J. Mas; S. Porres. Kimba a taula. Barcelona: Edebé, 2002.

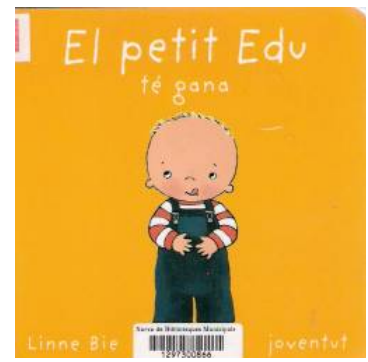

Ilustración 6. (C) L. Bie. ¡A comer! Barcelona: Juventud, S. A., 2004.

\section{El baño}

\begin{tabular}{|c|c|}
\hline $\begin{array}{l}\text { Marco argumental: } \\
\text { texto }\end{array}$ & $\begin{array}{l}\text { - Argumentos desde diferentes ejes: la contradicción (Maulet), la comparación } \\
\text { (Marc i la Maria es banyen), la sutil simplicidad (Els banys). } \\
\text { - Los protagonistas son los pequeños con escasa presencia de la familia. } \\
\text { Desenlaces mostrando el baño como hábito agradable, a excepción del siempre } \\
\text { contradictorio Maulet. }\end{array}$ \\
\hline $\begin{array}{l}\text { Marco argumental: } \\
\text { ilustración }\end{array}$ & $\begin{array}{l}\text { - Cierto simbolismo lúdico al utilizar animales como protagonistas y un rico } \\
\text { imaginario al que es proclive este hábito. } \\
\text { - Combinación de vía empática afectiva (formas redondeadas) e ingeniosa } \\
\text { (formas angulosas). }\end{array}$ \\
\hline $\begin{array}{l}\text { Entorno físico y } \\
\text { psicológico }\end{array}$ & $\begin{array}{l}\text { - Los espacios refuerzan la confianza, los aspectos lúdicos y rituales. } \\
\text { - Presencia materna mayoritaria. } \\
\text { - Los objetos transaccionales imitan los pasos del protagonista que deposita en } \\
\text { ellos el afecto. } \\
\text { - Juego temporal variado: divertidos “antes” (Maulet); intensos, lúdicos y dulces } \\
\text { “durante” y “después” para el resto de propuestas. }\end{array}$ \\
\hline Formato editorial & $\begin{array}{l}\text { - Inclusión de solapas o páginas desplegables dando ritmo a la narración. } \\
\text { - Presencia de ofertas lúdica, afectiva y educativa, predominando la primera. }\end{array}$ \\
\hline
\end{tabular}


Tabla 3. Análisis del corpus de cuentos sobre el hábito de bañarse

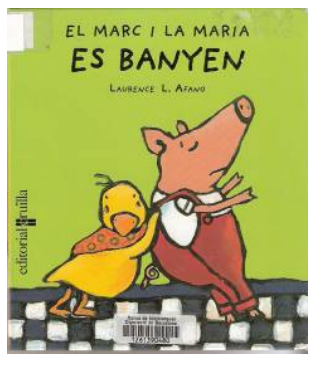

Ilustración 7. (C) L. Afano. El Marc i la Maria es banyen. Barcelona: Cruïlla, 2001

(C) Bruxelles; Rainbow Grafics Intl-Baronian Books, 2001

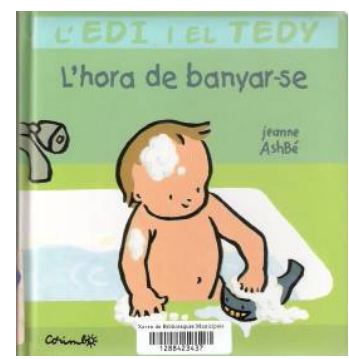

Ilustración 8. (C) J. Ashbé. L'hora de banyarse Barcelona: Corimbo, 2004. Traducción al catalán: Anna Coll-Vinent. Título de la edición original: « L’Heure du bain ». Paris: L’école de loisirs, 2003.

\section{Buenas noches}

\begin{tabular}{|c|c|}
\hline $\begin{array}{l}\text { Marco argumental: } \\
\text { texto }\end{array}$ & $\begin{array}{l}\text { - Una única narración visual (Al llit) y un discurso literario más intenso (Bona } \\
\text { nit, lluna) muestran variedad de argumentos. } \\
\text { - Figura paterna dominando por primera vez. } \\
\text { - Aparición de personajes imaginarios o reales (dragones, abuelas). } \\
\text { - Tono afectivo y ritual ante la frontera desconocida del sueño con miedos y } \\
\text { mundos desconocidos, superados en los desenlaces. }\end{array}$ \\
\hline $\begin{array}{l}\text { Marco argumental: } \\
\text { ilustración }\end{array}$ & $\begin{array}{l}\text { - Fuerte carga de ilustración simbólica. } \\
\text { - Los protagonistas, animales o humanos, se expresan prioritariamente por vía } \\
\text { empática afectiva, reforzada ésta por el ingenio. }\end{array}$ \\
\hline $\begin{array}{l}\text { Entorno físico } \quad y \\
\text { psicológico }\end{array}$ & $\begin{array}{l}\text { - Ir a dormir es el hábito que presenta más mecanismos psicológicos de ayuda, } \\
\text { por lo que los entornos muestran los rituales y los mecanismos de confianza. } \\
\text { - Las figuras familiares son muy activas tanto en la ritualización como en la } \\
\text { resolución de los problemas. } \\
\text { - Aparición de personajes imaginarios y objetos transaccionales. } \\
\text { - Este hábito introduce el hábito de la lectura e invita a la cadencia de la } \\
\text { narración de cuentos antes de dormir. }\end{array}$ \\
\hline Formato editorial & $\begin{array}{l}\text { - Domina el formato de tapa dura. } \\
\text { - Ofertas afectivas, lúdicas y educativas con hegemonía de la primera tipología. }\end{array}$ \\
\hline
\end{tabular}

Tabla 4. Análisis del corpus de cuentos sobre el hábito de ir a dormir

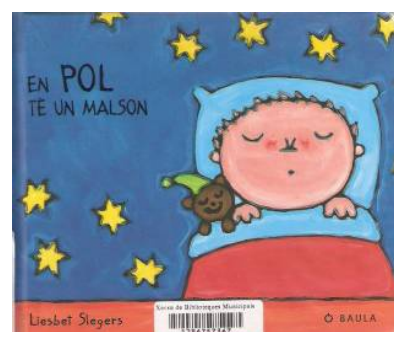

Ilustración 9. ㄷ L. Slegers. En Pol té un malson. Barcelona : Baula, 2003.

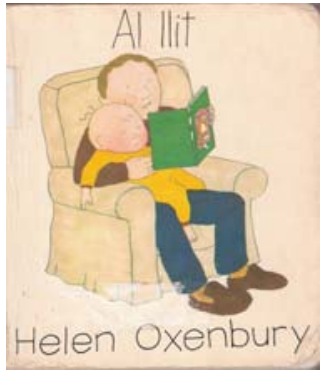

Figura 10 @ H. Oxenbury. Al llit. Barcelona: Juventud, S. A., 2004. 
Adiós a los pañales

\begin{tabular}{|c|c|c|}
\hline $\begin{array}{l}\text { Marco argumental: } \\
\text { texto }\end{array}$ & & $\begin{array}{l}\text { - Los argumentos tienen dos ejes: afectivo y lúdico. } \\
\text { - El orinal es el objeto propulsor de infinitas y ricas propuestas narrativas. } \\
\text { - Los pequeños son los protagonistas acompañados de progenitores y otros } \\
\text { personajes, reforzados por la figura de un narrador. } \\
\text { - El tono literario aparece en algunas propuestas, destacando El arte de la } \\
\text { baci y Tothom hi va. }\end{array}$ \\
\hline $\begin{array}{l}\text { Marco argumental: } \\
\text { ilustración }\end{array}$ & & $\begin{array}{l}\text { - La carga simbólica del hábito promueve una ilustración afectiva e } \\
\text { ingeniosa. } \\
\text { - Humor, cotidianeidad y efecto sorpresa están presentes }\end{array}$ \\
\hline $\begin{array}{l}\text { Entorno } \\
\text { psicológico }\end{array}$ & $\mathbf{y}$ & $\begin{array}{l}\text { - Distintos entornos muestran la necesaria relación lúdica y simbólica con el } \\
\text { hábito. } \\
\text { - El ensayo/error y las urgencias se reflejan en el conjunto de las historias. } \\
\text { - Los personajes que acompañan las historias son diversos y variopintos, lo } \\
\text { cual ahorra objetos transaccionales concretos. }\end{array}$ \\
\hline Form & & $\begin{array}{l}\text { - La carga creativa conlleva mayor presencia del formato álbum. } \\
\text { - Combinación del formato afectivo, lúdico y educativo en todas las } \\
\text { aventuras. }\end{array}$ \\
\hline
\end{tabular}

Tabla 5. Análisis del corpus de cuentos sobre el hábito del control de esfínteres

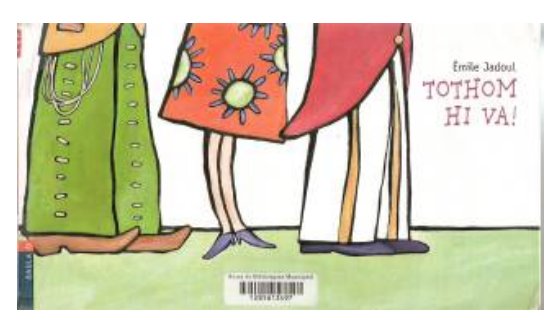

Ilustración 11. (C) E. Jadoul. Tothom hi va! Barcelona: Baula, 2004.

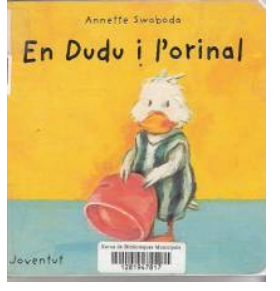

Figura 12. (C) A. Swoboda. En Dudu i l'orinal. Barcelona: Juventud, S.A, 2002.

\section{Concluyendo}

La lectura transversal de las categorías propuestas ofrece una panorámica de los hábitos, que nos lleva a considerar una serie de conclusiones: Domina la narración textual en la oferta editorial sobre hábitos del sí mismo. Pocos productos cualitativamente descompensados abogan por la narración visual (a destacar un clásico que no ha sido superado hoy por hoy: los pequeños cuentos de Helen Oxenbury, como Al llit). Los textos se simplifican o complican según si los hábitos desarrollan un argumento más lúdico o simbólico, respectivamente. En estos últimos, la dificultad del texto no radica en su amplitud -como en El arte de la baci o Ruby, anem a dinar, álbumes que invitan a narrar más porque contienen más- sino en el planteamiento de abstracciones que 
abordan regresiones, transgresiones y búsqueda de autonomía y que por ello requieren el apoyo de otros recursos, visuales o del lenguaje narrado (sería el caso de Em vesteixo i et menjaré, Lleva't o Bona nit, lluna).

El protagonista es quien habitualmente narra, apoyado a veces en un narrador ajeno a la historia. Los demás personajes que aparecen suelen formar parte de la familia: domina la figura materna, excepto en el hábito de las buenas noches, donde el padre aparece recordando la figura patriarcal que llega tarde a casa y acuesta a los niños.

En tono afectivo, se introduce ya el juego entre realidad y simbolización. Los desenlaces no rígidos muestran la consecución feliz del hábito, excepto en el caso de Maulet. Sin embargo, bajo esta homogeneización se esconden distintas tipologías:

-Circulares: empiezan y acaban en un mismo punto (Lleva't).

-Sugerentes: abiertas a otro posible final (Em vesteixo i et menjaré; Tothom hi va; Bona nit, lluna).

-Estáticas: aparecen como fotos fijas en el tiempo (Kimba a taula; A rentar-se!).

-Clásicas: marcadas por la temporalidad de los acontecimientos que se suceden (son la mayoría).

La muestra acoge una ilustración simbólica en la caracterización de personajes como animales con vida humana, ya como protagonistas, ya como actores secundarios. En casos como El bany de Piggy Wiggy; Bona nit, lluna; Tothom hi va; Lleva't o Em vesteixo... i et menjaré!, el simbolismo va más allá, planteando la apertura a otros mundos de ficción que proceden de los cuentos, los viajes, el surrealismo, etc. El hábito del adiós a los pañales es el que recoge una relación simbólica más ligada al componente humano y crea una ilustración que juega con los objetos, las comparaciones y el ensayo/error.

La narrativa visual se balancea entre la vía empática afectiva y la vía ingeniosa. Ambas conviven o se divorcian, como ocurre en las mejores familias, cuando el tono lúdico en la narración textual se impone, ofreciendo guiños de humor (És hora de banyar-se, Maulet, Lleva't...).

El entorno psicológico de los pequeños abarca:

-La soledad confiada del niño que muestra paso a paso el hábito, bien desde el alejamiento puramente didáctico (A rentar-se), bien desde la cercanía de poder identificarse y reconocerse con la ayuda de un mayor que narra la historia (La meva roba o El petit Edu té gana). 
-La contención de las figuras familiares, principalmente la materna -explícita o intuidaaunque con una cada vez más acusada representación del padre como ser también capaz de contención afectiva y emocional hacia el pequeño.

-Los entresijos relacionales que se mueven entre el protagonista y los objetos o muñecos son una de las aportaciones positivas de esta selección: la mayoría de ellos cobran vida y conviven también con el hábito desde lo que Winnicott (citado en Torres 2006: 109) llamó la “zona transaccional” o zona de intercambio, manifestada en las edades tempranas a partir de las propias experiencias corporales con los hábitos y que favorece la “creatividad de vivir" y las primeras simbolizaciones, que permiten tolerar las primeras ausencias, confiando en los vínculos preestablecidos.

El entorno físico muestra espacios y objetos cotidianos, lo que permite desarrollar un juego de identificación que se concentra en el hábito (Quan és hora d'anar al llit, L'hora de banyar-se,...) o que incluso va más allá, acercando el mundo exterior que rodea diariamente al pequeño (Bona nit!; Bona nit, lluna...), conformando así un mundo compartido y contenido desde lo ya conocido por el bebé.

La mayoría de las historias sincronizan las experiencias corporales de los hábitos, midiendo el argumento según el “tiempo del cuerpo” (Torres 2006: 116), favoreciendo así el proceso de estructuración del pensamiento. Las diferencias entre ellas se establecen en que:

-Unos tiempos se centran en mostrar regresiones o deseo de autonomía (Bon profit, Max, No tinc gana!...),

-Otros, en cambio, se pasean por el hábito de principio a fin (Fora bolquer, La meva roba...)

-Y el resto abre el tiempo real al tiempo imaginario (Lleva't; Bona nit, lluna).

Los criterios editoriales de los libros sobre hábitos parecen decantarse por un formato de cuento capaz de ser manejado por las manos más pequeñas. Comúnmente llamamos a estos formatos libros de tapa dura, que tienden a ser cuadrados. Tímidamente aparecen álbumes capaces de acoger una narración más simbólica que abren generosamente la puerta a una nueva forma de mirar lo literario.

El análisis constata que los ejes editoriales de estos libros están bordados por tres hilos que se trenzan afectiva, educativa y lúdicamente, siendo la primera la hebra más fuerte en lo tocante a iniciar el día, comer y acabar el día, pero pasando al último lugar cuando de bañarse y decir adiós a los pañales se trata. 


\section{Cerrando el círculo: puntos de encuentro entre editores, familias y mediadores}

El libro puede ser una primera visita a una galería de arte para un niño; podría ser un pequeño museo de palabras e ilustraciones para hacer que el lector se sienta a gusto, libre y feliz. Es un "espacio abierto" para dar y recibir ideas. (Pacovská 2006: 143)

Como apunta Rateau (2005: para 18), el libro destinado a la primera infancia no es un producto. El trabajo esencial de los adultos, sean editores, mediadores o adultos responsables de cuidarle, es acompañar al niño en su deseo de experimentar y comprender el mundo en que vive. El problema es que el desencuentro nos aturde y caminamos entre mundos que a menudo nos separan. Acompañar al niño/a no quiere decir mostrar. Acompañar significa concedernos el permiso para aprender de la compleja realidad psíquica infantil. “A nosotros nos corresponde transmitir esa otra dimensión sensible del libro y la lectura que va más allá de la literalidad del significado” (Colomer 2005: 95), dejándonos seducir por ella. Será el niño quien pondrá sus cinco sentidos y nosotros permaneceremos atentos a su lado. Porque si de vista, olfato, oído, gusto y tacto se trata, ellos pueden servirnos de guía para que familias, editores y mediadores nos encontremos en los distintos cruces de este camino que necesariamente tendremos que recorrer juntos.

\section{¡Libro a la vista!}

Es necesaria una educación que vaya rompiendo ese impulso familiar por comprar los cuentos según su atractivo y sorprendente formato. Se tiende demasiado a equiparar las ilustraciones de este tipo de historias a imágenes dulces y planas que no permiten ver más allá de la realidad (Duran 2006: 97). Es evidente que un niño de 8 meses a 1 año irá construyendo su capacidad visual paulatinamente, pero su afectividad es todo un universo y su capacidad empática de imaginarse en una imagen determinada ya sea “encantadoramente amable” o “menos amanerada” (Duran 2002: 43) es otro universo.

Agradeceríamos que algunos editores equilibraran su producción ofreciendo libros sobre los hábitos en la pequeña infancia basados en criterios de calidad visual.

Escuela, bibliotecas y librerías podrían invitar a leer viendo, ofreciendo herramientas de selección, destacando aquellas historias de la cotidianidad del pequeño mundo infantil que ofrezcan diferentes vías coherentes para mirarlas. 


\section{Mil y un aromas}

Despertar el buen olfato en las familias supone construir puentes entre editores y mediadores que provoquen el deseo de aprender y el riesgo de decidir y proponer. Para ello, seguir las huellas del trabajo realizado en otros países, como Francia, en el que la lectura en la primera infancia es objeto de estudio y divulgación, nos imprime la fuerza para emular el proceso llevado a cabo.

Posiblemente, los mediadores adolecemos aún de una falta de rigor práctico a la hora de construir esquemas y criterios de análisis que permitan tamizar las obras destinadas a la pequeña infancia (Dupont-Escarpit 2006: 14). Investigar, elaborar periódicamente guías temáticas que, como en el caso de la francesa Tout petit tu lis y otros buenos ejemplos, son recurso indispensable para seguir el rastro olfativo de las buenas lecturas vinculares.

\section{Algo que contar}

Explicar historias que se nos presentan como cotidianas al oído de los pequeños es un tramo del camino lúdico y emocional de la lectura. Por esta razón, aquellos libros que, además de narración visual, presentan también una narración textual deben cuidarse. Aunque su dimensión sea reducida, sería aconsejable que se pensara en ellos para ser narrados por una voz que les proporcione cadencia. Para Teresa Duran (2002), “un libro mudo no es un libro sin texto, sino una obra en la que ni la imagen ni el texto nos transmiten nada” (p. 92). Los editores deberían esmerarse y no alumbrar esas “ediciones mudas”, ni obras de buenos autores-ilustradores que, una vez traducidas, tienen una deficiente sintaxis u ortografía.

El niño en edad temprana siempre necesita palabras que le ayuden a identificarse a partir de los objetos reales o imaginarios. Para ello, las familias deben contar, relatar, ir a las bibliotecas a escuchar y a hablar sobre los cuentos. "Leer a los pequeños en voz alta no es tanto una cuestión de técnica (...), es una cuestión de vida” (Rateau 2005: para 16).

\section{Un pellizco de sal y un terrón de azúcar}

Cuando el diseñador e ilustrador de álbumes infantiles Paul Rand se enfrentaba a su obra, siempre lo hacía desde el contraste, “convirtiendo lo ordinario en extraordinario" (Carbonell 2006: 15). Posiblemente, ésta sea una buena definición del buen gusto, condición necesaria para vérselas con el libro destinado a los más pequeños como un 
espacio de creación ofrecido por los editores. Orientar su trabajo para experimentar esta concepción del libro, compartida con las familias y con la colaboración de los mediadores, restaría poder a la concepción del libro como objeto de consumo efímero (Duran 1981: 27).

El puente que un niño recorre entre aquello “que puede reconocer fácilmente (en un libro ilustrado) y lo que puede comprender a través de un esfuerzo imaginativo que sea suficientemente recompensado” (Colomer 2005: 77) requiere de una literatura que se comprometa, en el caso de la pequeña infancia, a viajar desde el detalle del mundo de lo cotidiano hasta la metáfora de la imaginación que permite ya otros niveles de lectura. Y para este viaje, se requieren libros editados que se muevan entre la placidez del bebé que aprende, el humor que lo condimenta todo y la puerta que se abre a regresiones, provocaciones y transgresiones.

\section{Acariciar el círculo}

Mientras una parte importante de la sociedad siga buscando un determinado tema que ilustre un libro para los más pequeños y no una buena historia que hable sobre..., no se acabará de cerrar el círculo que proponemos. Tendremos, entonces, que acariciar las líneas para darles forma, intentando que editores y mediadores creamos que se pueden ofrecer buenas y excelentes lecturas de literatura infantil para las primeras edades. Es sólo una cuestión de respeto hacia la infancia.

Arrimar el hombro es tarea difícil, pero los mediadores especializados en el campo de la lectura y la literatura infantil no pueden quedarse en la neutralidad. Desde el deseo de objetividad -siempre difícil- el compromiso de nuestro trabajo debe considerar todo cuanto de subjetivo, discutible y posible tienen las buenas lecturas vinculares y abrir un espacio vital como punto de encuentro ya que, como dice Marie Manuellian (citada en Rateau 2001), “cada pequeño es único, cada momento es único, cada circunstancia de lectura es única. La elección de un libro ha de basarse en el equilibrio entre dos aspectos: el universal y el individual. Atreverse a la aventura y ofrecer la aventura” (p. 53), entre otras, la del día a día.

\section{Referencias bibliográficas}

AAVV (2001) Muchos libros para niños: una guía para reconocerlos y nombrarlos. Caracas: Banco del Libro. 
AAVV (2001b) ¿Qué libros, para qué edad?: cómo escoger el libro adecuado. Caracas: Banco del Libro.

Aberasturi, A. (2002) El niño y sus juegos. Buenos Aires: Paidós.

Afano, L. L. (2001) El Marc i la Maria es banyen. Barcelona: Cruïlla.

Ashbé, J. (2004) L’hora de banyar-se. Barcelona: Corimbo.

Berner, R. (2002) Bona nit! Barcelona: Barcanova.

Biblioteques de Barcelona (2005) El món de l'infant: 0 a 3 anys [guía de lectura]. Barcelona: Consorci de Biblioteques de Barcelona.

Biblioteques de Barcelona (2006) L'aventura del dia a dia [Guía de lectura] Barcelona: Consorci de Biblioteques de Barcelona.

Bie, L. (2004) El petit Edu té gana. Barcelona: Juventud.

Bonnafé, M. (2006) Les livres, c'est bon pour les bébés.Paris: Hachette Littératures.

Brown, M.W. (2003) Bona nit, lluna. Barcelona: Corimbo.

Bruel, C. (2003) Les jeunes lectures durent toujours. La Revue des livres pour les enfants, 214, Dècembre, pp. 82-93.

Butterworth, N. (2001) Quan és hora d'anar al llit. Barcelona: Juventud.

Carbonell, P. (2006) Paul Rand para todos. Revista de Literatura, 222, pp. 13-17.

Claverie, J. (2003) El arte de la baci. Santa Marta de Tormes: Lóguez.

Colomer, T. (2005) Andar entre libros: la lectura literaria en la Escuela. México: Fondo de Cultura Económica.

Dubois, C.-G. (2001) Fora bolquer! Barcelona: Corimbo.

Dupont-Escarpit, D. (2006) Leer un álbum ¡es fácil! En: Asociación Cultural Peonza. El arte y el álbum ilustrado [Monográfico] Peonza, 75/76, Abril, pp. 7-21.

Duran, T. (1981) El libre i l'infant abans dels sis anys. In-fàn-cia, 2, Setembre/Octubre: 24-27.

Duran, T. (2002) Leer antes de leer. Madrid: Anaya.

Duran, T. (2006) En el ruedo de la ilustración. En: Asociación Cultural Peonza. El arte y el álbum ilustrado [Monográfico] Peonza, 75/76, Abril, pp. 91-103.

Duran, T. (2007) Àlbums i altres lectures: anàlisi dels llibres per a infants. Barcelona: Asociació De Mestres Rosa Sensat.

Fox, C. (2001) El bany de Piggy Wiggy. Barcelona: Timun Mas.

Geis, P.i Folch, S. (2006) A rentar-se! Barcelona: Combel.

Geisler, D. (2002) Bon profit, Max! Barcelona: Juventut.

Ginesta, M. (2004) Lleva't. Barcelona: Abadia de Montserrat.

Guettier, B. (2000) Em vesteixo... i et menjaré! Barcelona: Corimbo.

Gutman, A.; Hallensleben, Georg (2003) Els banys. Barcelona: Juventud.

Jadoul, E. (2004) Tothom hi va! Barcelona: Baula.

Kitamura, S. (2002) És hora de banyar-se, Maulet. Sant Cugat del Vallès: Símbol.

Lionni, L. (2005) Antes de las imágenes. En: El libro álbum: invención y evolución de un género para niños, pp. 150-155. Caracas: Banco del Libro.

Mas, J.; Porres, S. (2002) Kimba a taula. Barcelona: Edebé.

Nascuts per llegir (2006) Salta Miralta: El ritme de les paraules en els contes per als més petits [guía de lectura]. Barcelona: Nascuts per llegir.

Nascuts per llegir (2007) A dins i a fora: el dia a dia dels més petits [guía de lectura]. Barcelona: Nascuts per llegir.

Oxenbury, H. (2004) Al llit. Barcelona: Juventud.

Pacovská, K. (2006) El arte del libro ilustrado y yo. En: Asociación Cultural Peonza. El arte y el álbum ilustrado [Monográfico] Peonza, 75/76, Abril, pp. 143-145.

Persson, L. (2003) La meva roba. Barcelona: La Galera.

Rateau, D. (2001) Des livres d'images pour tous les ages. Toulouse: Erès. 
Rateau, D. (2005) Entretien avec Dominique Rateau Les entretiens de Ricochet. Visto 27 de noviembre de 2008 en http://www.RicochetJeunes.Org/Entretien.Asp?Id=111.

Rius, M.; Rius, R. (2004) No tinc gana! Barcelona: Combel.

Rogers, E.; Rogers, P. (2003) Ruby, anem a dinar! Barcelona: Timun Mas.

Silva-Díaz, M. C. (2005) La metaficción como un juego de niños: una introducción a los álbumes metaficcionales. Caracas: Banco del Libro.

Silva-Díaz, M. C. (2006) La función de la imagen en el álbum. En: Asociación Cultural Peonza. El arte y el álbum ilustrado [Monográfico] Peonza, 75/76, Abril, pp. 2333.

Steiner, D. (1996) Comprendiendo a tu hijo de 1 año. Barcelona: Paidós.

Torres, E. (2005) La palabra amorosa. Revista Barataria, 4: 17-20.

Torres, E. (2006) Trabajando con los más jóvenes del planeta. En : AAVV. Trabajando con los más jóvenes del planeta. Caracas: Larense.

Referencia de la autora:

Nati Calvo Buil es Diplomada en Trabajo Social y en Biblioteconomía y Documentación por la Universitat de Barcelona. Tiene el título de Master en Libros y Literatura para Niños y Jóvenes por la UAB y el Banco del Libro de Venezuela. Es miembro del primer grupo de trabajo promotor del proyecto Nascuts per Llegir en Catalunya y miembro de la Comisión de Selección del Premi Atrapallibres del Consell Català del Llibre Infantil i Juvenil y del Grup de Treball d'Àrees Infantils i Juvenils del Col-legi Professional de Bibliotecaris-Documentalistes de Catalunya. Ha participado como autora de artículos y comunicaciones en diferentes jornadas y congresos sobre literatura infantil y biblioteca pública, además de como moderadora y docente. Es responsable del Servei de Documentació de Literatura Infantil i Juvenil del Consorci de Biblioteques de Barcelona.

Email: calvobn@diba.cat

\footnotetext{
1 "Jean Le Boulch [...] plantea que necesitamos vivir las sensaciones en tiempo presente en un cuerpo vivido desde el sentir, para luego poder imaginarlas, desarrollar la capacidad de recordar y nombrar lo ausente en un cuerpo percibido y poder así llevarlas a un planteamiento expresivo, que hable, que dé forma a un sentir y una percepción ordenadas por un cuerpo capaz de representar" (Torres 2006: 101). Es interesante, pues, atender a esta producción editorial sobre hábitos ya que es un primer eslabón en la formación lectora de cada niño/a.

${ }^{2}$ Las autoras colectivas de las guías de lectura utilizadas como base de la selección final son Nati Calvo, Montse Fàbregas, Marta García, Glòria Gorchs, Esther Granados, Yolanda Martí y Sílvia Rabat. Para más información este proyecto: www.nascutsperllegir.org

${ }^{3}$ Proyectos como Nati per Leggere en Italia, Bookstart en Gran Bretaña, Born to read y Read out and reach en EUA, Leyendo espero en Salamanca (España).

${ }^{4}$ Disponible en línea: http://www.bcn.es/biblioteques/docs/aventura_del_diaadia_v2.pdf

${ }^{5}$ Teresa Duran, en su estudio Álbums i altres lectures (2007) enumera también otras vías comunicativas de la ilustración no representadas en el corpus seleccionado y que, por tanto, no se han considerado.

${ }^{6}$ No es objeto de este trabajo describir estas tres etapas (Torres 2005) -dos según otros autores (Herrera 1994) que, a grosso modo, abarcan la consolidación de la construcción del "yo", la búsqueda de autonomía, la identificación del otro, el reconocimiento de las emociones, la imitación y el descubrimiento de la fantasía desde su deseo de comprender el mundo que lo circunda.

${ }^{7}$ En Francia, por ejemplo, dada su larga tradición de escuela psicoanalítica lacaniana, autores como Marie Bonnafé, Marion Durand, o Dominique Rateau, entre otros, han estudiado en profundidad los aspectos derivados de las vías narrativas a desarrollar en la literatura destinada a la edad temprana.

En Venezuela, Colombia y otros países latinoamericanos se ha focalizado más la atención en la producción que permite ofrecer al bebé una lectura afectiva en voz alta (Torres 2005).

${ }^{8}$ Las descripciones bibliográficas de los libros seleccionados aparecen en las referencias.

${ }^{9}$ Para Winnicott, el "objeto transaccional" es el objeto-símbolo que permite la ausencia de la madre y favorece el proceso de discriminación (citado en Torres 2006: 109).
} 